\title{
Quality of Life of Patients Followed for Thyroid Cancer: An Element Not to Overlook
}

\author{
Nassim Essabah Haraj, Siham El Aziz and Asma Chadli* \\ Endocrinology Department of CHU Ibn Rochd of Casablanca. Neuroscience laboratory. Faculty of Medicine and Pharmacy of Casablanca, \\ University Hassan II. Morocco
}

Received: April 17, 2018; Accepted: May 16, 2018; Published: May 24, 2018

*Corresponding author: Asma Chadli, Service d'endocrinologie. CHU Ibn Rochd. 1, Rue des Hôpitaux. Code postale : 20360, Casablanca. Maroc. Tel : +212 6 61092820; E-mail: drachadli@gmail.com

\section{Abstract}

The quality of life has attracted great interest in recent years, primarily in patients followed for cancer.

Differentiated thyroid cancer, despite its good prognosis, is responsible for a significant deterioration in the quality of life found in several studies.

Many factors affecting the quality of life were found in the studies, including radioiodine therapy and its dosage, the use of rh-TSH, total thyroidectomy and lymph node dissection, the stage of cancer, hormone treatment with TSH suppression, age and sex.

Particular attention should be paid to patients being followed for thyroid cancer, to restore their quality of life, especially in the presence
\end{abstract} of factor affecting the quality of life.

Keywords: Thyroid Cancer; Quality Of Life; Radioiodine Therapy

\section{Introduction}

Thyroid cancer is the most common endocrine cancer, and its incidence is increasing worldwide, especially because of the availability and evolution of diagnostic means [1]. It reaches $4 /$ 100000 inhabitants in men and 13.5 / 100000 in women, with a stable mortality in the order of $0.5 / 100000[1,2]$.

This increase in the number of cases of thyroid cancer is mainly related to the increase of infracentimetric papillary carcinomas which represent about $40 \%$ of all cancers $[1,3]$.

This raises the problem of over diagnosis of these small tumors that do not influence the survival but alter the quality of life (QoL) of the patient, [1] their diagnosis turns the patient status from a healthy subject to a cancerous subject.

Indeed, although thyroid cancer is a cancer of good prognosis, the diagnosis of cancer remains difficult to accept and has a significant impact on the quality of life.

The concept of quality of life is a recent concept, which is in constant evolution. Its main dimensions include environmental, social and economic factors [4].
Several studies have focused on analyzing the quality of life in patients treated for differentiated thyroid cancer [5-10] and the latest recommendations aim at a better adaptation of our practices towards a less aggressive handling of patients undergoing followup for differentiated thyroid cancer (DTC). [11,1]

Through this article, we will analyze several publications that raise the issue of the deterioration of quality of life in patients followed for differentiated thyroid cancer, and look for the factors described in the literature that significantly influence this quality of life.

\section{Discussion}

The concept of quality of life appeared in the United States in the 1950s, and initially meant a good material standard of living. $[12,13]$

In the 1960s, the concept acquired several dimensions: education, health, well-being, are also an integral part of the quality of life. [12,13]

WHO defines QoL as "an individual's perception of their position in life in the context of the culture and value systems in which they live and in relation to their goals, expectations, standards and concerns." [14]

In cancer research, it is now considered a major criterion of judgment used in the same way as other clinical criteria. [12,13]

To date, many quality of life questionnaires have been developed and validated, among them many are used in cancer patients.

Some are generic questionnaires such as the SF36 [15], the EuroQol [16], others generic tools are used more often with cancer patients, like the FLIC [17], and the FACT-G [18].

Generic questionnaires are nonspecific and can also be used on the general healthy population, thus allowing comparison of study groups to healthy control groups.

There are also specific questionnaires that are specific to a situation, to a pathology (thyroid, multiple sclerosis, 
schizophrenia...), to an age category (children, adolescents) or to a modality of care (palliative care...). [19,20]

For the thyroid, we can find ThyPRO and the EORTC QoL Questionnaires, which are specific to thyroid pathology [21,22]

The handling of patients undergoing treatment for differentiated thyroid cancer involves three basic steps: surgery, radioiodine therapy and hormone treatment with TSH suppression.

The patient's journey involves the intervention of several doctors: the general practitioner, the surgeon, the isotope specialist and the endocrinologist. Each one has a fundamental role in the announcement and explanation of the disease and therapeutic steps; a good doctor / patient relationship can often reassure patients and act positively on the quality of life. [23]

Several studies show $[5,6,7,8,9,10,24,25]$ a large variation in the perception of the disease in subjects treated for differentiated thyroid cancer, generally unrelated to favorable clinical follow-up of the disease.

Quality of life scores are generally reduced in patients treated for DTC. $[5,6,7,8]$

Some studies have compared the quality of life in patients treated for thyroid cancer with healthy control groups, including the Hoftijzer study [26], which compared the quality of life in a group of subjects followed for DTC with two control groups. One was comprised of healthy subjects selected by the patients themselves, and the other group was comprised of healthy subjects enrolled in other quality studies of life, matched for age, sex and socio-economic level. The study used 4 QoL questionnaires, and concluded a significant decrease in the quality of life in the cancer group compared to control groups.

Other studies have compared the quality of life of patients treated for thyroid cancer with other types of cancer, and have found a QoL similar or sometimes more altered than with other cancers that have darker prognoses, like breast cancer and colorectal cancer.

Many factors are influencing the quality of life of patients followed for differentiated thyroid cancer:

\section{Radioactive iodine treatment and the use of rh-TSH}

Although the side effects of Radioiodine therapy are minimal, and serious complications are rare [27], Radioiodine therapy has been found to be significantly associated with impaired quality of life in several studies [28,29]

The study by Nygaard et al [30] studied the effect of using rhTSH. Better quality of life was found in the group that uses rh-TSH compared to hypothyroidism by discontinuation of treatment; this can be explained by the deleterious effect of the symptoms of hypothyroidism.

Several other studies have reported the benefit of rh-TSH on quality of life. [31]

In the study by Almeida [28] a dose of radioactive iodine $\geq$ $150 \mathrm{mCi}$ was responsible for impaired quality of life.
The type of surgery (total thyroidectomy and lymph node dissection):

Surgery is usually the most stressful time for patients, the idea of dissection in the cervical region, the fear of postoperative complications, and the idea of a lifetime treatment after the thyroidectomy is responsible for a major anxiety. A good explanation of the procedure by the surgeon helps to reassure patients. [5]

Some studies [32,33] have analyzed the impact of thyroidectomy on the quality of life of patients with thyroid cancer, a better esthetic result and a minimum of pain allows to have a better quality of life. Post-thyroidectomy scars on the neck affect the QoL of thyroid cancer patients regardless of scar type. Therefore, clinicians should pay attention to the psychological effects of scars on patients and take care to minimize postthyroidectomy scar [5]

In Almeida's study [28], radical neck dissection was among the factors that negatively affected the quality of life.

\section{Cancer stage}

Many studies found a more altered quality of life in the advanced stages of cancer, essentially in patients with lymph node or distant metastases, or with local extension. This could be explained by the more aggressive treatment used in these cases, along with the need for multiple radioiodine therapy sessions.

Guisti et al [7] analyzed the quality of life in 128 patients using 3 quality of life questionnaires (Ad Hoc TQ, Hamilton depression and anxiety), the quality of life was more impaired in advanced stages.

\section{Hormonal balance}

Hormone treatment with TSH suppression is an important part of the therapeutic care of patients. Keeping patients with subclinical hyperthyroidism may be responsible for impaired quality of life, as well as cardiovascular and bone risks. [34]

This element has been controversially found in studies, the Hoftijzer et al study concluded that subjects monitored for DTC have an impairment of quality of life regardless of TSH levels. [26]

\section{Duration of evolution of the disease}

Despite the remission, the excellent prognosis and the nonaggressive treatment, patients with CDT have a decrease in quality of life that may only be restored after years of followup; the quality of life sometimes remains impaired despite the remission.

Several authors have suggested that quality of life restores to normal after prolonged follow-up, and this duration has been determined between 12 and 20 years. [6,8,26]

\section{Demographic criteria} of life.

This is essentially the impact of age and gender on the quality

Taïeb et al [35] indicated that elderly patients and those with a more severe stage of the disease have lower quality of life 
scores, and determined the age limit that influences quality of life at age 45 .

Metallo et al indicated that quality of life would be better in young patients. [36]

\section{Psychosomatic interventions and behavioral support}

A study in China [37] has shown that psychological and behavioral interventions can play an important role in improving the quality of life.

Physical exercise can also reduce the anxiety due to the treatment as highlighted in a Brazilian study [38], which showed that a 60 minutes twice à week program, consisting of aerobic and stretching exercises, can reduce significantly the negative impact of treatment on QoL.

This underlines the importance of looking for patients in pain and offering them programs that can improve their well-being.

\section{Conclusion}

The symptoms and treatment of cancer usually results in a series of profound changes in the mental and psychological capacity of patients.

An alteration of the quality of life is often found after the discovery of thyroid cancer. Several factors are at play, including the stage of the cancer, the radioiodine therapy and its dosage, the use of rh-TSH, the surgical procedure, hormone treatment with TSH suppression, the age and sex of the patient.

Great attention should be given to the psychological wellbeing of patients especially in the presence of risk factors that impair the quality of life.

\section{References}

1. S Zerdoud, S Leboulleux, J Clerc, L Leenhardt, C Bournaud, A Al Ghuzlan, et al. Traitement par iode 131 des cancers thyroïdiens différenciés : recommandations 2017 des sociétés françaises SFMN/ SFE/SFP/SFBC/AFCE/SFORL. Médecine nucléaire 2017.

2. La Vecchia C, Malvezzi M, Bosetti C, Garavello W, Bertuccio P, Levi F, et al. Thyroid cancer mortality and incidence: a global overview. Int J Cancer. 2015;136(9):2187-2195. Doi: 10.1002/ijc.29251

3. Vaccarella S, Franceschi S, Bray F, Wild CP, Plummer M, Dal Maso L. Worldwide thyroid-cancer epidemic? The increasing impact of overdiagnosis. N Engl J Med 2016;375(7):614-617. Doi: 10.1056/ NEJMp1604412

4. Brousse C. Réflexion sur la qualité de vie. La revue de médecine interne. 2007;28(7):441-442. Doi: 10.1016/j.revmed.2007.01.006

5. Bãrbuș E, Peștean C, Larg M, Piciu D. Quality of life in thyroid cancer patients: a literature review. Clujul Medical 2017;90(2):147-153. Doi: 10.15386/cjmed-703

6. Crevenna R, Zettinig G, Keilani M, Posch M, Schmidinger M, Pirich C, et al. Quality of life in patients with non-metastatic differentiated thyroid cancer under thyroxine supplementation therapy. Support Care Cancer. 2003;11(9):597-603. Doi: 10.15386/cjmed-703

7. Giusti M, Sibilla F, Cappi C, Dellepiane M, Tombesi F, Ceresola E, et al. A case-controlled study on the quality of life in a cohort of patients with history of differentiated thyroid carcinoma. J Endocrinol Invest. 200;28(7):599-608.

8. Dagan T, Bedrin L, Horowitz Z, Chaushu G, Wolf M, Kronenberg J, Talmi YP. Quality of life of well-differentiated thyroid carcinoma patients. J Laryngol Otol. 2004;118(7):537-542. Doi: 10.1258/0022215041615137

9. Schultz PN, Stava C, Vassilopoulou-Sellin R. Health profiles and quality of life of 518 survivors of thyroid cancer. Head Neck. 2003;25(5):349356. Doi: $10.1002 /$ hed.10217

10. Tan LG, Nan L, Thumboo J, Sundram F, Tan LK. Health-related quality of life in thyroid cancer survivors. Laryngoscope 2007;117(3):507-510. Doi: 10.1097/MLG.0b013e31802e3739

11. Haugen BR, Alexander EK, Bible KC, Doherty GM, Mandel SJ, Nikiforov YE, et al. 2015 American Thyroid Association Management Guidelines for Adult Patients with Thyroid Nodules and Differentiated Thyroid Cancer: The American Thyroid Association Guidelines Task Force on Thyroid Nodules and Differentiated Thyroid Cancer. Thyroid. 2016;26(1):1-133. Doi: 10.1089/thy.2015.0020

12. Chassany 0 , Caulin C. Qualité de vie liée à l'état de santé : critère d'évaluation. Recherche et décision thérapeutique. Edition spinger. 2003

13. Steudler F. Les enjeux et les acteurs de la promotion de la qualité de vie. Cancer, Sida, la qualité de vie, sous la direction de Claude Jasmin Jay, A Levy et Gabriel Bez. 1996.

14. World Health organization. WHOQOL: Measuring Quality of Life. 2017.

15. Ware JE, Sherbourne CD. The MOS 36-item short-form health survey (SF-36). I. Conceptual framework and item selection. Med Care. 1992;30(6):473-483.

16. EuroQol Group. EuroQol--a new facility for the measurement of health related quality of life. Health Policy. 1990;16(3):199-208.

17. Schipper H, Clinch J, McMurray A, Levitt M. Measuring the quality of life of cancer patients: the Functional Living Index-Cancer: development and validation. J Clin Oncol. 1984;2(5):472-483. Doi: 10.1200/ JC0.1984.2.5.472

18. Cella DF, Tulsky DS, Gray G, Sarafian B, Linn E, Bonomi A,et al. The Functional Assessment of Cancer Therapy scale: development and validation of the general measure. J Clin Oncol. 1993;11(3):570-579. Doi: 10.1200/JC0.1993.11.3.570

19. Hunt S. La qualité de vie : un cas de mesure possible. Cancer, Sida, la qualité de vie, sous la direction de Claude Jasmin Jay, A Levy et Gabriel Bez. 1996.

20. Vernay D, Gerbaud L, Clavelou P. Qualité de vie et sclérose en plaque. Revue de Neurologie (Paris). 2001;157(8-9):1139-1142. Doi: RN-092001-157-8-9-C2-0035-3787-101019-ART33

21. Watt T, Hegedus L, Groenvold M, Bjornerm JB, Rasmussen AK, Bonemma SJ, Feldt-Rasmussen U. Validity and reliability of the novel thyroid-specific quality of life questionnaire, ThyPRO. Eur J Endocrinol. 2010;162(1):161-167. Doi: 10.1530/EJE-09-0521

22. Singer S, Jordan S, Locati LD, Pinto M, Tomaszewska IM, Araújo C, et al. The EORTC module for quality of life in patients with thyroid cancer: phase III. Endocr Relat Cancer. 2017;24(4):197-207. Doi: 10.1530/ ERC-16-0530.

23. Greer S, Watson M. Mental adjustment to cancer: its measurement and 
prognostic importance. Cancer Surv. 1987;6(3):439-453.

24. Schultz PN, Beck ML, Stava C, Vassilopoulou-Sellin R. Health profiles in 5836 long-term cancer survivors. Int J Cancer. 2003;20;104(4):488495. Doi: $10.1002 / \mathrm{ijc} .10981$

25. Hirsch D, Ginat M, Levy S, Benbassat C, Weinstein R, Tsvetov G, et al. Illness perception in patients with differentiated epithelial cell thyroid cancer. Thyroid. 2009;19(5):459-465. Doi: 10.1089/thy.2008.0360

26. Hoftijzer HC, Heemstra KA, Corssmit EP, van der Klaauw AA, Romijn JA, Smit JW. Quality of life in cured patients with differentiated thyroid carcinoma. J Clin Endocrinol Metab. 2008;93(1):200-203. Doi: $10.1210 /$ jc.2007-1203

27. Maier H, Bihl H. Effect of radioactive iodine therapy on parotid gland function. Acta Otolaryngol. 1987;103(3-4):318-324

28. Almeida JP, Vartanian JG, Kowalski LP. Clinical Predictors of Quality of Life in Patients With Initial Differentiated Thyroid Cancers. Arch Otolaryngol Head Neck Surg. 2009;135(4):342-346. Doi: 10.1001/ archoto.2009.16

29. Gamper EM, Wintner LM, Rodrigues M, Buxbaum S, Nilica B, Singer $S$, et al. Persistent quality of life impairments indifferentiated thyroid cancer patients: results from a monitoring programme. Eur J Nucl Med Mol Imaging. 2015;42(8):1179-1188.

30. Nygaard B, Bastholt L, Bennedbæk FN, Klausen TW, Bentzen J. A placebo-controlled, blinded and randomised study on the effects of recombinant human thyrotropin on quality of life in the treatment of thyroid cancer. Eur Thyroid J. 2013;2(3):195-202. Doi: $10.1159 / 000354803$

31.Tu J, Wang S, Huo Z, Lin Y, Li X, Wang S. Recombinant human thyrotropin-aided versus thyroid hormone withdrawal-aided radioiodine treatment for differentiated thyroid cancer after total thyroidectomy: a meta-analysis. Radiother Oncol. 2014;110(1):25-30. Doi: 10.1016/j.radonc.2013.12.018
32. Choi Y, Lee JH, Kim YH, Lee YS, Chang HS, Park CS, et al. Impact of postthyroidectomy scar on the quality of life of thyroid cancer patients. Ann Dermatol. 2014;26(6):693-699. Doi: 10.5021/ad.2014.26.6.693

33. Dimov RS. The effect of neck dissection on quality of life in patients with differentiated thyroid cancer. Gland Surg. 2013;2(4):219-226. Doi: 10.3978/j.issn.2227-684X.2013.10.06

34. Donangelo I, Braunstein GD. Update on subclinical hyperthyroidism. Am Fam Physician. 2011;83(8):933-938.

35. Taïeb D, Baumstarck-Barrau K, Sebag F, Fortanier C, De Micco C, Loundou A, et al. Heath-related quality of life in thyroid cancer patients following radioiodine ablation. Health Qual Life Outcomes. 2011;9:33. Doi: 10.1186/1477-7525-9-33

36. Metallo M, Groza L, Brunaud L, Klein M, Weryha G, Feigerlova E. Long-Term Quality of Life and Pregnancy Outcomes of Differentiated Thyroid Cancer Survivors Treated by Total Thyroidectomy and I131 during Adolescence and Young Adulthood. Int J Endocrinol. 2016; 2016: 7586482. Doi: 10.1155/2016/7586482

37. Wu HX, Zhong H, Xu YD, Xu CP, Zhang Y, Zhang W. Psychological and behavioral intervention improves the quality of life and mental health of patients suffering from differentiated thyroid cancer treated with postoperative radioactive iodine-131. Neuropsychiatr Dis Treat. 2016;12:1055-1560. Doi: 10.2147/NDT.S105460

38. Vigário Pdos S, Chachamovitz DS, Teixeira Pde F, Rocque Mde L, Santos ML, Vaisman M. Exercise is associated with better quality of life in patients on TSH-suppressive therapy with levothyroxine for differentiated thyroid carcinoma. Arq Bras Endocrinol Metabol. 2014;58(3):274-281. 